\title{
Sclerotherapy for the Management of Rectal Prolapse in Children
}

AUTHORS: Scott C. Dolejs MD ${ }^{1}$, Justin Sheplock ${ }^{1}$, Robert J. Vandewalle MD ${ }^{1}$, Mathew P. Landman MD MPH ${ }^{1}$, Frederick J. Rescorla MD ${ }^{1}$

AFFILIATION:

${ }^{1}$ Indiana University School of Medicine, Division of Pediatric Surgery

CORRESPONDING AUTHOR:

Frederick J. Rescorla MD

705 Riley Hospital Dr \#2500

Pediatric Surgery

Indianapolis, IN 46202

Telephone: $317-274-4682$

Fax: 317-274-4491

Current E-mail: frescorl@iupui.edu

DISCLAIMERS: Dr.'s Dolejs, Sheplock, Vandewalle, Landman, and Rescorla have no conflicts of interest to disclose.

FUNDING: There is no funding for this paper.

AUTHOR CONTRIBUTION:

Study Conception and Design: Scott Dolejs, Justin Sheplock, Frederick Rescorla

Data Acquisition: Scott Dolejs, Frederick Rescorla, Justin Sheplock

Analysis and Data Interpretation: Scott Dolejs, Matthew P. Landman, Frederick Rescorla

Drafting of the Manuscript: Scott Dolejs, Justin Sheplock, Robert Vandewalle

Critical Revision: Scott Dolejs, Justin Sheplock, Robert Vandewalle, Matthew P. Landman,

Frederick Rescorla

RUNNING TITLE: Sclerotherapy for rectal prolapse

This is the author's manuscript of the article published in final edited form as:

Dolejs, S. C., Sheplock, J., Vandewalle, R. J., Landman, M. P., \& Rescorla, F. J. (2017). Sclerotherapy for the Management of

Rectal Prolapse in Children. Journal of Pediatric Surgery. https://doi.org/10.1016/j.jpedsurg.2017.10.015 


\section{ABSTRACT:}

PURPOSE: Rectal prolapse is a commonly occurring and usually self-limited process in children. Surgical management is indicated for failures of conservative management. However, the optimal approach is unknown. The purpose of this study is to determine the efficacy of sclerotherapy for the management of rectal prolapse.

METHODS: This was a retrospective review of children $<18$ years with rectal prolapse who underwent sclerotherapy, predominantly with peanut oil (91\%), between 1998 and 2015. Patients with imperforate anus or cloaca abnormalities, Hirschprung disease, or prior pullthrough procedures were excluded.

RESULTS: Fifty-seven patients were included with a median age of 4.9 years (interquartile range (IQR) 3.2-9.2) and median follow-up of 52 months (IQR 8-91). Twenty patients ( $n=20 / 57$; $35 \%$ ) recurred at a median of 1.6 months (IQR 0.8-3.6). Only 3 patients experienced recurrence after 4 months. Nine of the patients who recurred $(n=9 / 20 ; 45 \%)$ were re-treated with sclerotherapy. This was successful in 5 patients $(n=5 / 9 ; 56 \%)$. Two patients $(n=2 / 20 ; 10 \%)$ experienced a mucosal recurrence which resolved with conservative management. Forty-four patients were thus cured with sclerotherapy alone ( $n=44 / 57 ; 77 \%$ ). No patients undergoing sclerotherapy had an adverse event. Thirteen patients $(n=13 / 20 ; 65 \%)$ underwent rectopexy after failing at least one treatment of sclerotherapy. Three of these patients $(n=3 / 13 ; 23 \%)$ recurred following rectopexy and required an additional operation.

CONCLUSIONS: Injection sclerotherapy for children with rectal prolapse resulted in a durable cure of prolapse in most children. Patients who recur following sclerotherapy tend to recur within 4 months. Another attempt at sclerotherapy following recurrence is reasonable and was successful half of the time. Sclerotherapy should be the preferred initial treatment for rectal prolapse in children and for the initial treatment of recurrence.

KEYWORDS: Rectal prolapse; Sclerotherapy

LEVEL OF EVIDENCE: Level IV 
TYPE OF STUDY: Treatment Study 


\section{INTRODUCTION:}

Rectal prolapse is a relatively common condition in children that typically occurs before the year of four, around the time toilet training begins [1-4]. It is most frequently idiopathic and self-limited and resolves with improved toileting habits and stool softeners within one year in the majority of patients [1-6]. If prolapse persists despite optimal management, various strategies exist for treatment. These include injection sclerotherapy [4-17], encircling of the anus, also known as the Thiersch operation $[10,18]$, abdominal operations $[3,13,19,20]$, and perineal operations [10, 21]. Given the varied approaches, no one technique currently predominates thereby creating a wide heterogeneity in practice patterns.

Sclerotherapy has several potential advantages including its minimally invasive nature and low complication profile [4]. We seek to determine the success of injection sclerotherapy in patients with rectal prolapse who failed conservative management in a large, tertiary academic center. We also aim to characterize factors associated with failure of sclerotherapy to determine if there are patients who may benefit from initial operative management.

\section{MATERIALS AND METHODS:}

This is a single institution retrospective review of patients less than 18 years old who underwent injection sclerotherapy for rectal prolapse between 1998 and 2015. Patients with imperforate anus or cloaca abnormalities, Hirschprung's disease, or prior pull-through procedures were excluded. Additionally, two patients who underwent primary rectopexy were excluded. Appropriate institutional review board approval was obtained prior to initiating the study.

Patients with rectal prolapse were treated via a standard pathway. This standard pathway included initial medical management with fiber supplementation in all patients. If patients had constipation, they were treated with laxatives. Behavior modification was used in all patients which included minimizing time on the toilet and avoiding. If medical management failed to resolve the prolapse in 1-3 months, patients were considered for injection sclerotherapy. The 
surgery was performed by multiple surgeons at a single hospital. Pre-operative preparation involved decompression of the rectum with an enema or suppository with intra-operative irrigation as needed. Patients were placed in the lithotomy position under general anesthesia. A digital rectal examination was performed to rule out the presence of rectal polyps or other abnormalities. The majority of patients received $5 \%$ phenol in peanut oil as the sclerosing agent, which was compounded by the pharmacy department and then dry-heat sterilized with a batch sent to microbiology for sterility testing prior to release of the dose for patient use. Alternative sclerosant agents included $5 \%$ phenol in almond oil or concentrated dextrose solutions $(25 \%$ or higher) and were utilized based on patient allergy profiles. The agent was administered via direct injection into the submucosal tissue, beginning at the dentate line and extending approximately $8 \mathrm{~cm}$ proximally up the rectal wall. This was performed in 4 -quadrants around the rectum.

Statistical analysis was performed with SAS version 9.4 (SAS Institute Inc, Cary, NC). Continuous variables were not normally distributed; thus, median values with interquartile range (IQR) are displayed. Univariate analysis was conducted with Chi-square, Fisher's exact test, or Wilcoxon-Rank Sum tests as appropriate.

\section{RESULTS:}

Fifty-seven patients undergoing injection sclerotherapy were included for analysis. Patient demographics, operative characteristics, and post-operative results are given in Table 1. Patients were followed for a median of 52 months (IQR: 7.6-91.0 months).

Phenol in peanut oil was the predominant sclerosant used $(n=51 / 57 ; 91 \%)$. Three patients with a peanut allergy underwent sclerotherapy with phenol in almond oil and two patients with nut allergies underwent sclerotherapy with concentrated dextrose solution. The median volume of sclerosant was $10 \mathrm{~mL}$ (IQR: 10-15 mL) and the median sclerosant volume per $\mathrm{kg}$ was $0.5 \mathrm{~mL} / \mathrm{kg}$ (IQR: 0.3-0.8 mL/kg). Sclerotherapy was performed as an outpatient 
procedure in all cases and none of the patients undergoing sclerotherapy experienced a postoperative complication.

Recurrence occurred in 20 patients ( $n=20 / 57 ; 35 \%)$ (Figure 1). The majority of patients $(n=17 / 20 ; 85 \%)$ experienced recurrence in the first four months after sclerotherapy. In two of the patients with recurrence $(n=2 / 20 ; 10 \%)$, medical management of their constipation resulted in resolution of prolapse without further operative management. Nine patients ( $n=9 / 20 ; 45 \%)$ underwent repeated sclerotherapy. This was successful in five patients ( $n=5 / 9 ; 56 \%)$. Three patients were cured after 2 total rounds of sclerotherapy, one person was cured after 3 total rounds of sclerotherapy, and one person was cured after 4 total rounds of sclerotherapy, with treatment intervals from one months to several years. Thus, in total, sclerotherapy alone resulted in a durable cure of rectal prolapse in forty-four patients $(n=44 / 57 ; 77 \%)$. Four patients who underwent repeated sclerotherapy $(n=4 / 9 ; 44 \%)$ eventually required a rectopexy. One of these four patients required a sigmoidectomy and Hartmann pouch after failed rectopexy. Nine patients underwent rectopexy after one attempt at sclerotherapy. Two of these patients required another operation for rectal prolapse. This involved an excision of rectal procidentia with anastomosis via a perineal approach in one patient and a sigmoidectomy via abdominal approach in another patient. Thus, thirteen total patients $(n=13 / 20 ; 65 \%)$ with recurrence following sclerotherapy underwent a rectopexy. Three of these patients $(n=3 / 13 ; 23 \%)$ recurred and required another operative intervention.

In evaluating factors associated with recurrence, older age, higher weight, and sclerosant other than phenol in peanut oil were all significantly associated with recurrence ( $p$ value $<0.05$ ). All patients who used phenol in almond oil or dextrose solution experienced a recurrence. Two of the three patients with recurrence following phenol in almond oil sclerotherapy required rectopexy and the other patient was cured with repeated sclerotherapy. Both patients with recurrence after dextrose injection sclerotherapy were cured with repeated sclerotherapy. Higher sclerosant volume was associated with recurrence ( $p$-value=0.02). 
However, there was no association with sclerosant volume and recurrence after standardization patient weight ( $p$-value $=0.41)$.

In evaluating factors associated with eventual success of sclerotherapy or eventual requirement of operative management, similar factors to recurrence were associated with requirement for eventual operation, but the differences in groups are larger (Table 4). Patients who required operative management were 7.9 years older on average and $28 \mathrm{~kg}$ heavier on average. There was a patient who was 18 years old and another who weighed $71 \mathrm{~kg}$ whose rectal prolapse was cured with sclerotherapy alone.

\section{DISCUSSION:}

In our single center retrospective review that spanned over 15 years, fifty-seven patients who underwent primary injection sclerotherapy for rectal prolapse were examined. This represents one of the largest series of injection sclerotherapy in the current literature. Our results demonstrate that the first sclerotherapy results in durable cure of prolapse in $68 \%$ of patients and repeat sclerotherapy will eventually result in a durable cure of prolapse in $77 \%$ of patients. This cure rate is similar to the current literature, in which injection sclerotherapy has been found to result in durable cure $70-95 \%$ of the time $[4,5,8,9,11-13,15,16]$. If a recurrence occurred, it most commonly occurred within the first four months, indicating that sclerotherapy also results in durable cure in the majority of our patients. Further, sclerotherapy was performed as an outpatient procedure in all cases and no complications occurred in patients who underwent sclerotherapy. While there have been reports of death following injection sclerotherapy due to phenol toxicity, the vast majority of reports on injection sclerotherapy have shown sclerotherapy is safe with minimal complications $[4,5,8,9,11-13$, $15,16,22]$. One report noted an association of abscess formation with injection sclerotherapy with phenol in almond oil, and it may be that our process of dry-heat sterilization combined with batch culture prior to utilization in patients prevented this complication from occurring [15]. 
Injection sclerotherapy represents a safe, minimally invasive, and efficacious treatment of rectal prolapse.

Despite its efficacy, thirteen patients eventually required an abdominal operation to treat their rectal prolapse. In our evaluation of factors associated with recurrence and eventual need for operative management, several significant factors were noted. First, in comparing different sclerosants, our results demonstrate that all patients with phenol in almond oil and dextrose experienced recurrence. Both patients with dextrose sclerotherapy resolved with repeated sclerotherapy, but two of the three patients with phenol in almond oil required operative management. Phenol in almond oil has been found to be an effective sclerosant compared to cow's milk, $30 \%$ saline solution, $30 \%$ dextrose solution, and $70 \%$ ethyl alcohol solution [23]. In another study, phenol in almond oil was effective in all patients, but was associated with a $9 \%$ rate of abscess and mucosal sloughing in $27 \%$ [15]. In light of these studies and our study, phenol in peanut oil or concentrated dextrose should be the preferred sclerosant agent. In regards to volume, although there was not a statistically significant association, patients without recurrence had a median volume of $0.50 \mathrm{~mL} / \mathrm{kg}$ of sclerosant compared with $0.38 \mathrm{~mL} / \mathrm{kg}$ in patients who experienced a recurrence. Thus, a volume of $0.50 \mathrm{~mL} / \mathrm{kg}$ of sclerosant divided over four quadrants appears a prudent volume to treat rectal prolapse.

Our study also highlights that older patients who weigh more are more likely to experience recurrence and eventually need an operation. This is congruent with prior studies that have investigated a relationship between age and recurrence following prolapse [13]. This has led other studies to recommend early definitive corrective surgery in older children (older than 5 years old) who do not respond to conservative measures or injection sclerotherapy [13]. However, our results also highlight that patients as old as 18 years old or who weigh as much as $71 \mathrm{~kg}$ were successfully treated with sclerotherapy. Thus, a trial of sclerotherapy and at least one additional sclerotherapy appear reasonable given the favorable complication profile of this technique. Further, even amongst the thirteen patients who underwent surgical repair, three 
required an additional operation $(n=3 / 13 ; 23 \%)$, indicating that surgery itself is not a guarantee of successful resolution of prolapse.

These findings need to be viewed in light of limitations inherent in this method of investigation. One important potential limitation is that it is unknown how many of these patients would have had resolution of their prolapse without any treatment. While all patients were given a trial of conservative measures, we cannot know how many of the patients who underwent operative intervention would have had resolution of their symptoms without operative intervention. Another important limitation is potential losses to follow-up. While we had a robust median follow-up of 52 months and were able to utilize a statewide database to see if patients were treated at other facilities, it is still possible there were recurrences that were not captured as a result of the retrospective nature of this study. Thus, this study may overestimate the effectiveness of injection sclerotherapy. Another limitation is low power and number of events. In particular, a multivariable analysis would be able to better define which factors are independently associated with recurrence. Unfortunately, with only twenty events of recurrence and only thirteen patients requiring operative management, we would only be able to include two factors into this analysis rendering this technique not particularly useful in our series.

\section{CONCLUSIONS:}

Injection sclerotherapy is an effective treatment strategy for children with rectal prolapse. It should be the first-line treatment in patients who fail a trial of conservative management. Repeat injection sclerotherapy should be the favored approach for recurrence. In older and heavier patients, consideration for earlier operative intervention should be considered. However, even these patients can benefit from a trial of injection sclerotherapy with a repeated treatment should a recurrence occur. 


\section{CITATIONS:}

1. Qvist N, Rasmussen L, Klaaborg KE, et al: Rectal prolapse in infancy: conservative versus operative treatment. J Pediatr Surg 21:887-888, 1986

2. Corman ML: Rectal prolapse in children. Dis Colon Rectum 28:535-539, 1985

3. Laituri CA, Garey CL, Fraser JD, et al: 15-Year experience in the treatment of rectal prolapse in children. J Pediatr Surg 45:1607-1609, 2010

4. Antao B, Bradley V, Roberts JP, et al: Management of rectal prolapse in children. Dis Colon Rectum 48:1620-1625, 2005

5. Abes M, Sarihan $\mathrm{H}$ : Injection sclerotherapy of rectal prolapse in children with 15 percent saline solution. Eur J Pediatr Surg 14:100-102, 2004

6. Batool T, Akhtar J, Ahmed S: Management of idiopathic rectal prolapse in children. Jcpsp, Journal of the College of Physicians \& Surgeons - Pakistan 15:628-630, 2005

7. $\quad$ Sahay R, Murthi G, Lindley R: Outcomes following sclerotherapy for mucosal rectal prolapse with oily phenol injection: single-centre review. Pediatr Surg Int, 2016

8. Sarmast $\mathrm{MH}$, Askarpour S, Peyvasteh M, et al: Rectal prolapse in children: a study of 71 cases. Przeglad gastroenterologiczny 10:105-107, 2015

9. Tokunaga Y: Clinical utility of sclerotherapy with a new agent for treatment of rectal prolapse in patients with risks. J Clin Gastroenterol 48:356-359, 2014

10. Flum AS, Golladay ES, Teitelbaum DH: Recurrent rectal prolapse following primary surgical treatment. Pediatr Surg Int 26:427-431, 2010

11. Zganjer M, Cizmic A, Cigit I, et al: Treatment of rectal prolapse in children with cow milk injection sclerotherapy: 30-year experience. World J Gastroenterol 14:737-740, 2008

12. Hachiro $\mathrm{Y}$, Kunimoto $\mathrm{M}$, Abe $\mathrm{T}$, et al: Aluminum potassium sulfate and tannic acid injection in the treatment of total rectal prolapse: early outcomes. Dis Colon Rectum 50:19962000, 2007

13. Shah A, Parikh D, Jawaheer G, et al: Persistent rectal prolapse in children: sclerotherapy and surgical management. Pediatr Surg Int 21:270-273, 2005

14. Sasaki Y, Iwai N, Kimura O, et al: The treatment of rectal prolapse in children with phenol in almond oil injection. Eur J Pediatr Surg 14:414-417, 2004

15. Fahmy MA, Ezzelarab S: Outcome of submucosal injection of different sclerosing materials for rectal prolapse in children. Pediatr Surg Int 20:353-356, 2004

16. Chan WK, Kay SM, Laberge JM, et al: Injection sclerotherapy in the treatment of rectal prolapse in infants and children. J Pediatr Surg 33:255-258, 1998

17. Gysler R, Morger R: [Sclerosing treatment with ethoxysclerol in anal prolapse in children]. Z Kinderchir 44:304-305, 1989

18. Chauhan K, Gan RW, Singh S: Successful treatment of recurrent rectal prolapse using three Thiersch sutures in children. BMJ Case Rep 25:25, 2015

19. Puri B: Rectal prolapse in children: Laparoscopic suture rectopexy is a suitable alternative. J Indian Assoc Pediatr Surg 15:47-49, 2010

20. Montes-Tapia F, Cura-Esquivel I, Garza-Luna U, et al: Sigmoid fixation associated with rectopexy using a laparoscopic approach could prevent relapse of rectal prolapse in pediatric patients with spinal dysraphia. J Pediatr Surg 43:1551-1553, 2008

21. Tsiaoussis J, Chrysos E, Glynos M, et al: Pathophysiology and treatment of anterior rectal mucosal prolapse syndrome. Br J Surg 85:1699-1702, 1998

22. Philip AT, Marraffa JM: Death following injection sclerotherapy due to phenol toxicity. J Forensic Sci 57:1372-1375, 2012

23. Ezer SS, Kayaselcuk F, Oguzkurt P, et al: Comparative effects of different sclerosing agents used to treat rectal prolapse: an experimental study in rats. J Pediatr Surg 48:17381743, 2013 
Figure 1: Flowchart demonstrating the treatment pathway of patients with rectal prolapse recalcitrant to medical therapy who underwent primary sclerotherapy

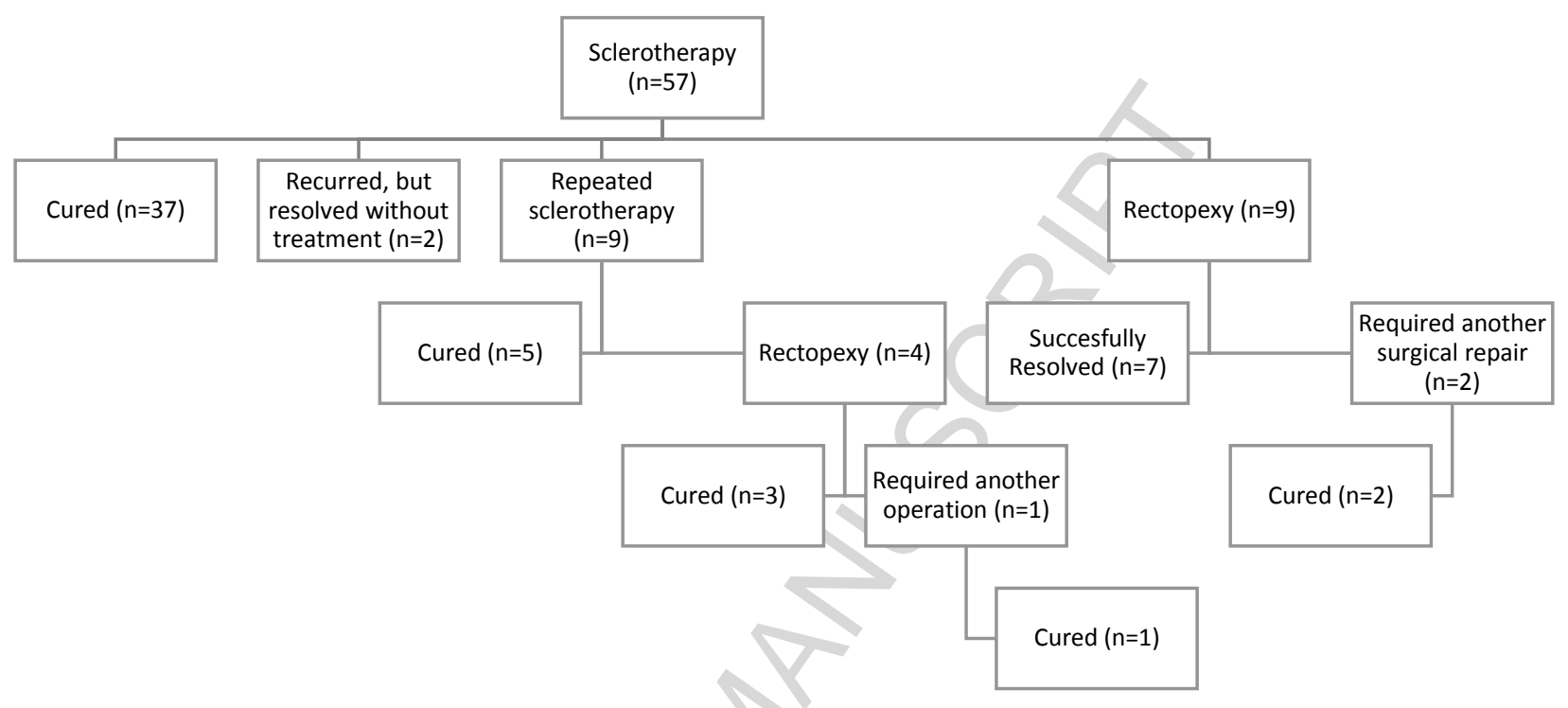


Table 1: Pre-operative, operative, and post-operative characteristics of patients undergoing injection sclerotherapy for recalcitrant rectal prolapse

n (\%) or Median (Interquartile Range)

Pre-operative Characteristics:

Gender (male, $n(\%)$ ):

Age (yrs; median (IQR)):

Weight (kg; median (IQR)):

Length of Follow-up (months; median

$(I Q R))$ :

\section{Operative Characteristics:}

Sclerosant Used (n (\%))*:

\begin{tabular}{l} 
Peanut oil with phenol: \\
\hline Almond oil with phenol: \\
Dextrose solution: \\
Sclerosant Volume ( $\mathrm{mL}$; median $(I Q R))$ : \\
Sclerosant Volume/Weight ( $\mathrm{mL} / \mathrm{kg}$; median \\
(IQR)):
\end{tabular}

Post-operative Complications:

Recurrence (n (\%)):

Sclerotherapy first for Recurrence (n (\%)):

Surgical Repair (n (\%)):

Resolved without surgery (n (\%)):

Length to Recurrence (months; median $(I Q R))$ :

$42(73.7 \%)$

$4.9(3.2-9.2)$

$20.0(15.0-34.0)$

$51.9(7.6-91.0)$
$20(35.1 \%)$

$9(45.0 \%)$

$13(65.0 \%)$

$2(10.0 \%)$

$1.6(0.8-3.6)$

* The sclerosant used was not charted in one patient 
Table 2: Pre-operative and operative factors associated with recurrence following primary sclerotherapy

\begin{tabular}{|c|c|c|c|}
\hline $\begin{array}{l}\text { Pre-operative and Operative } \\
\text { Factor }\end{array}$ & $\begin{array}{c}\text { No Recurrence } \\
(n=37)\end{array}$ & $\begin{array}{l}\text { Recurrence } \\
\quad(n=20)\end{array}$ & $\begin{array}{l}p- \\
\text { value }\end{array}$ \\
\hline Gender (male, $n(\%)$ ): & $29(78.4 \%)$ & $13(65.0 \%)$ & 0.27 \\
\hline Age (yrs; median (IQR)): & $4.2(3.0-5.9)$ & $8.2(4.8-13.4)$ & $<0.01$ \\
\hline Weight (kg; median (IQR)): & $18.0(14.5-21.5)$ & $37.0(23.0-53.0)$ & $<0.01$ \\
\hline Sclerosant Used $(n(\%))^{*}$ : & & & $<0.01$ \\
\hline Peanut oil with phenol: & $36(100.0 \%)$ & $15(75.0 \%)$ & \\
\hline Almond oil with phenol: & $0(0.0)$ & $3(15.0 \%)$ & \\
\hline Dextrose solution: & $0(0.0)$ & $2(10.0 \%)$ & \\
\hline Volume ( $m L ;$ median (IQR)): & $10.0(9.0-12.5)$ & $12.8(10.0-18.5)$ & 0.02 \\
\hline $\begin{array}{l}\text { Volume/Weight ( } \mathrm{mL} / \mathrm{kg} ; \text { median } \\
(I Q R)) \text { : }\end{array}$ & $0.50(0.37-0.77)$ & $0.38(0.29-0.78)$ & 0.41 \\
\hline
\end{tabular}

* The sclerosant used was not charted in one patient 
Table 3: Pre-operative and operative factors associated with eventual need for operative management following primary injection sclerotherapy

\begin{tabular}{|c|c|c|c|}
\hline $\begin{array}{l}\text { Pre-operative and } \\
\text { Operative Factor }\end{array}$ & $\begin{array}{c}\text { Resolved with } \\
\text { sclerotherapy alone } \\
(n=44)\end{array}$ & $\begin{array}{c}\text { Required operative } \\
\text { management } \\
(n=13)\end{array}$ & p-value \\
\hline Gender (male, $n(\%)$ ): & $34(81.0)$ & $8(61.5)$ & 0.29 \\
\hline $\begin{array}{l}\text { Age (yrs; median } \\
(I Q R)) \text { : }\end{array}$ & $4.6(3.0-6.2)$ & $12.5(6.5-14.3)$ & $<0.01$ \\
\hline $\begin{array}{l}\text { Weight (kg; median } \\
(I Q R)) \text { : }\end{array}$ & $18.0(15.0-23.0)$ & $46.0(29.0-70.0)$ & $<0.01$ \\
\hline $\begin{array}{l}\text { Sclerosant Used (n } \\
(\%))^{*} \text { : }\end{array}$ & & & 0.18 \\
\hline $\begin{array}{l}\text { Peanut oil with } \\
\text { phenol: }\end{array}$ & $40(93.0)$ & $11(84.6)$ & \\
\hline $\begin{array}{l}\text { Almond oil with } \\
\text { phenol: }\end{array}$ & $1(2.3)$ & $2(15.4)$ & \\
\hline Dextrose solution: & $2(4.7)$ & $0(0.0)$ & \\
\hline $\begin{array}{l}\text { Volume (mL; median } \\
(I Q R)) \text { : }\end{array}$ & $10.0(9.5-12.8)$ & $15.0(10.0-20.0)$ & 0.03 \\
\hline $\begin{array}{l}\text { Volume/Weight } \\
\text { (mL/kg; median } \\
(I Q R)):\end{array}$ & $0.50(0.38-0.77)$ & $0.34(0.23-0.49)$ & 0.06 \\
\hline
\end{tabular}

* The sclerosant used was not charted in one patient 


\section{SLEROTHERAPY FOR THE MANAGEMENT OF}

RECTAL PROLAPSE IN CHILDREN

Presented by Matthew Landman, Indianapolis IN

CARLOS (Knoxville, TN): Where specifically do you do your injections? The reason I am asking this question is that we also do it in four quadrants, but I had one patient who had transient loss of sensation, and I think it probably had to do with inflammation of the nerves around the area. This person became incontinent for about 2-3 weeks due to the loss of sensation, so we try to avoid the 3 and 9 o'clock positions for our injections. I wonder how you do it.

MATTHEW LANDMAN: We start at the dentate line, hopefully that gets around the innervation of the sphincter muscle, and then go proximally $8 \mathrm{~cm}$. We have found that there were no adverse events from these injections, so I think starting at the dentate line and going proximally may prevent that complication.

ROBERT BAIRD (Montreal, QC): Nicely presented. We learned yesterday that there is considerable variability in practitioner decision and the interval between first presentation to go to sclerotherapy. Can you enlighten us on how you decided to take your children for sclerotherapy? What were your indications?

MATTHEW LANDMAN: That's sort of the crux. When is enough time for medical management? All the patients that presented to our 
surgical clinic had essentially been maximally medically managed, and we didn't really look through the times, and that's kind of the next step in our process. From our standpoint, barring those patients who have difficult reductions or present to the emergency department frequently for reductions, that would be an indication for more urgent intervention. I think it is surgeon specific in our institution and there was no specific algorithm the time, unfortunately.

ROBERT BAIRD: I'd encourage you to drill down.

MATTHEW LANDMAN: We will.

RAMEN JAMSHIDI (Phoenix, AZ): Nice presentation on something where there's a dearth of literature, but a useful technique. To piggyback on the last question, what time interval did you allow for resolution of recurrences before proceeding with the second treatment?

MATTHEW LANDMAN: Based on this data and the practice, it's going to be less than a couple of months. I think if you don't have recurrence up front within that first two--month period, you can be a little bit more at ease about waiting longer. Within that first 1-2 months is a reasonable approach. 